http://jmscr.igmpublication.org/home/

ISSN (e)-2347-176x ISSN (p) 2455-0450

crossref DOI: https://dx.doi.org/10.18535/jmscr/v8i6.27

Journal Of Medical Science And Clinical Research

IGM Publication

An Official Publication of IGM Publication

\title{
Study of Functional Outcome of Surgical Management of Ipsilateral Femur and Tibia Fractures (Floating Knee)
}

\author{
Authors \\ Dr Sonu Thankachan ${ }^{1}$, Dr Jagajeev $\mathbf{J R}^{2^{*}}$, Dr Sabarisree $\mathbf{M}^{3}$ \\ ${ }^{1}$ Post graduate Student Medical College Hospital, Thiruvananthapuram \\ ${ }^{2}$ Addl. Professor, Dept of Orthopaedics, Govt Medical college Hospital, Thiruvanathapuram \\ ${ }^{3}$ Additional Professor in Orthopaedics, Govt Medical College, Thiruvananthapuram \\ *Corresponding Author \\ Dr Jagajeev JR
}

Addl. Professor, Dept of Orthopaedics, Govt Medical College Hospital, Thiruvanathapuram, India

\begin{abstract}
Aim and objective of study was to assess functional outcome of surgical management of patients having ipsilateral tibia and femur fracture using Karlstrom and Oleruds criteria. Secondary objective of the study was to identify factors affecting the eventual functional outcome of ipsilateral tibia and femur fracture.

Materials and Methods: A prospective observational study was conducted on 23 patients, who had undergone surgical treatment, for a period of one year after IEC approval.

Results: In $43 \%$ patients there was no restriction of knee movements, in $35 \%$ there was about less than 20 degree of knee movements and 18\% had moderate limitation (20-40degree) of knee movement. One patient had severe restriction of knee movement. The outcome was poor in intra articular fractures and comminuted fractures and excellent in patients who had primary fixation with intra medullary nails.

Conclusion: Internal fixation of floating knee with intramedullary nails followed by early mobilization give better functional outcome, though the results are poor in intra articular fractures.
\end{abstract}

\section{Review of Literature}

In 1970 s and 80 conservative management was the treatment of choice. This was associated with high incidence of delayed union, nonunion, malunion osteomyelitis and knee stiffness In 1975 Blake and Mc bryde reported a series of 47 patients. Delayed union 18 or non union occurred in $44.6 \%$ of total number of bones involved. In 1977Karlstorm and olerud reported 32 patients with floating knee injuries, fourteen patients were treated by rigid internal or external fixation for both fractures. Three patients had internal or external fixation of one fracture and conservative treatment of the other. Fifteen patients underwent non operative treatment of both fractures. An active surgical treatment produced considerably better functional end results. Clinical examination of the knee at the postoperative follow up suggested that disruption of ligaments (Collaterals or cruciate ligaments) was a common occurrence and should always be suspected in the presence of recurrent knee instabilities.

In 1972, Watson reported 24 patients who had non operative management

In 1979, De Lee reported treatment of floating knee injuries in seventeen patients with cast bracing of both fractures as definitive treatment. 
Shortening and malunion was common with this type of fractures.

In 1996, Gregory described retrograde nailing of the femur and unreamed nailing of the tibia. This was modified by Ostrum in 2000 by nailing both the tibia and femur through a percutaneous single incision.

A study by Rethnam et al in 2006 showed that associated injuries and type of fractures were important prognostic indicators.

Lundy DW, Johnson KD had given a brief outline on ipsilateral fractures of femur and tibia. The definition of floating knee injuries.

The definition is as follows Ipsilateral fracture of femur and tibia and may include combination of diaphyseal, metaphyseal and intra articular fractures.

Diaphyseal fractures are better than intraarticular fractures for the outcome. Functional assessment after treatment of floating knee injuries is evaluated by most authors using Karlstrom and Olerud grading system.

Classification for Floating Knee Injuries. Classification used for this study is Blake and Mcbrydes classification of floating knee injuries.

\section{Blake and Mcbrydes Classification}

Type-1: True floating knee.

The knee joint is isolated completely and not involved with either shafts fracture.

Type-2: Variant floating knee.

Involves one or major joints with either shaft fractured.

2A: Knee joint alone is involved.

2B: invoves the hip or ankle joints.

Femoral condyle fractures were classified into AO classification and tibialcondyle fractures were classified as Schatzker classification.

\section{Surgical Management of Floating Knee}

Femoral shaft fractures and distal femur fractures were managed according to the AO principles. Tibial condyle fractures can be treated surgically depending on the fracture pattern and Schatzker classification. Treatment option for Tibial shaft fractures include intramedullary nailing,

compression plating using LCP or DCP, Bridge plating or external fixator application. Surgical treatment of floating knee injuries in an unstable or ploy trauma patient needs observance of damage control orthopaedics first followed by definitive treatment. Prevention of wound sepsis by adequate debridement and irrigation of wound is the primary objective in compound fractures. Beyond these two basic methods there is difference of opinion as to the following.

1. Primary secondary wound closure.

2. Use of primary internal fixation.

\section{Complications of Floating Knee Injuries}

Early

1) Neurovascular Injury.

2) Fat Embolism

3) Compartment Syndrome.

4) Infection And Sepsis.

\section{Materials and Methods}

Prospective observational study was conducted on 23 patients with floating knee for a period of one year after IEC. All the patients were managed surgically in the Dept of orthopaedics, Govt Medical College, Thiruvanathapuram. The study included all ipsilateral femur and tibial fractures in adults and both closed and open fractures. Patients with neurological deficits due to spinal injuries were excluded from the study. All the patients were treated initially by emergency care as per ATLS protocol. The patients were classified according to blake and Mcbrydes classification for floating knee injuries. The patients were evaluated clinically and radiologically before surgery, at 6 weeks, 12 weeks and at 6 months. Functional outcome at 6 months was evaluated based on karlstorm and oleruds criteria

\section{Operative Techniques}

Surgical modalities were selected based on type of fracture and the nature of soft tissue. Most of the Gustilo and Anderson type -3 were debrided and temporarily stabilized in external fixator. Closed fractures and open fractures up to Gustilo and Anderson type 2 were treated with primary fixation based on fracture pattern either as 
emergency or as elective based on patients general condition and associated injuries. For closed diaphyseal fractures involving shaft of femur or tibia either interlocking intramedullary nails or locking compression plates were used. For metaphyseal fractures involving joint, locking compression plates or buttress plates as open reduction and internal fixation (ORIF) or minimal incision percutaneous osteosynthesis (MIPO) was done.

\section{Results and Analysis}

We studied 23 patients with floating knee injuries who were managed surgically in our department. The following are the observations made and available data are analysed as follows.

Table-1 Blake and Mcbryde classification

\begin{tabular}{|l|c|c|c|c|}
\hline Blake and Mcbryde's type & Type 1 & Type 2 a & Type 2 b & Total cases \\
\hline No: of patients & 15 & 7 & 1 & 23 \\
\hline
\end{tabular}

Table-2 Age distribution of patients

\begin{tabular}{|l|c|c|}
\hline Age Group (years) & No: of patients & Percentage \\
\hline$<20$ & 3 & $13 \%$ \\
\hline $21-30$ & 10 & $43 \%$ \\
\hline $31-40$ & 5 & $22 \%$ \\
\hline $41-50$ & 3 & $13 \%$ \\
\hline$>50$ & 2 & $9 \%$ \\
\hline
\end{tabular}

Figure-1 Gender distribution

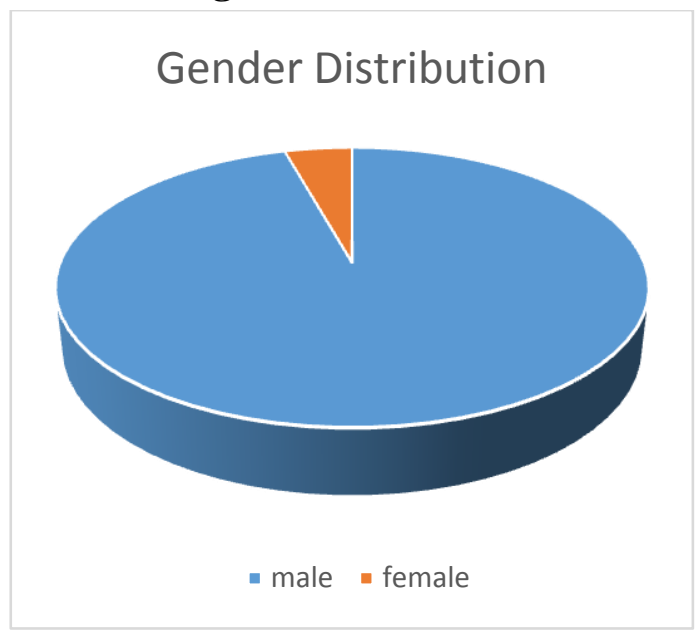

Figure-3 Mode of Injury

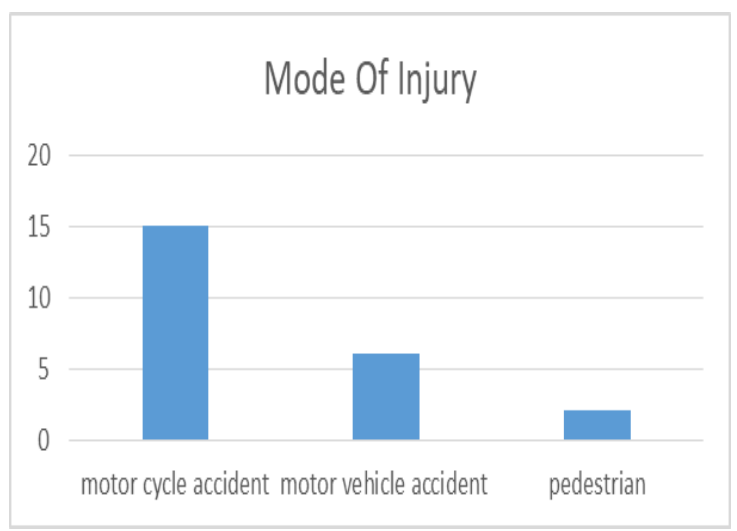

Figure-2 side of injury

\section{Side Of Injury}

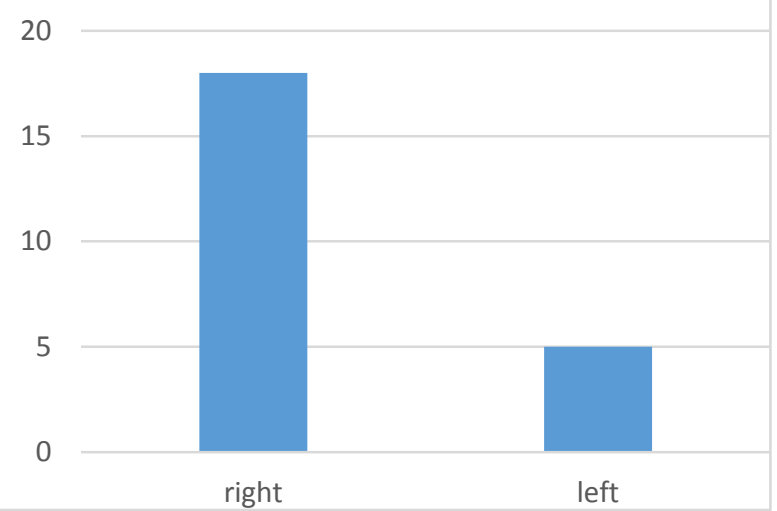

Figure-4 Floating Knee Injury

Floating Knee Injury

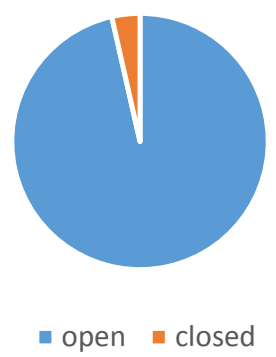


Table-3 Distribution of femur fractures

\begin{tabular}{|l|c|c|}
\hline Types & No. of fractures & percentage \\
\hline Closed & 18 & 78 \\
\hline Type 1 open & 1 & 4 \\
\hline Type 2 open & 4 & 18 \\
\hline Type 3 open & 0 & 0 \\
\hline
\end{tabular}

Table 4 Distribution of tibia fractures

\begin{tabular}{|c|c|c|}
\hline Types & No. of fractures & percentage \\
\hline Closed & 3 & 13 \\
\hline Type 1 & 6 & 26 \\
\hline Type 2 & 9 & 39 \\
\hline Type 3 & 5 & 22 \\
\hline
\end{tabular}

Table-5 Management of Tibia Fractures

\begin{tabular}{|l|c|c|}
\hline Type of fracture Tibia & Type of fixation & No of cases \\
\hline \multirow{2}{*}{ Type 3 open } & External fixator ILN Tibia & 4 \\
\cline { 2 - 3 } & External fixator LTBP & 1 \\
\hline \multirow{2}{*}{ Type 2 open } & ILN Tibia & 8 \\
\cline { 2 - 3 } & LTBP & 1 \\
\hline Type 1 open & ILN Tibia & 2 \\
\hline Closed & Plating & 4 \\
\cline { 2 - 3 } & Plating & 3 \\
\hline
\end{tabular}

Table-6 Management of Femur fractures

\begin{tabular}{|l|c|c|c|}
\hline $\begin{array}{l}\text { Type of fracture- } \\
\text { open/closed }\end{array}$ & Fracture pattern & Type of fixation & No. of cases \\
\hline \multirow{2}{*}{ Closed } & Intra-articular & LISS & 2 \\
\cline { 2 - 4 } & Extra-articular & LISS & 2 \\
\cline { 2 - 4 } Type 1 open & $\begin{array}{c}\text { Extra-articular- } \\
\text { segmental }\end{array}$ & ILN & 14 \\
\hline \multirow{2}{*}{ Type 2 open } & Intra-articular & LISS & 1 \\
\cline { 2 - 4 } & Extra-articular & ILN & 1 \\
\hline
\end{tabular}

Table-7 Functional outcome of patients

\begin{tabular}{|l|c|c|c|c|}
\hline & \multicolumn{4}{|c|}{ Outcome } \\
\hline Criteria & Excellent & Good & Acceptable & poor \\
\hline $\begin{array}{l}\text { Subjective } \\
\text { symptoms from thigh or leg }\end{array}$ & 10 & 6 & 7 & 0 \\
\hline Subjective symptoms from knee or ankle joint & 10 & 6 & 7 & 0 \\
\hline Walking ability & 11 & 6 & 5 & 1 \\
\hline Work \& sports & 4 & 10 & 9 & 0 \\
\hline Angulation, rotational deformity or both & 9 & 12 & 2 & 0 \\
\hline Shortening & 9 & 12 & 1 & 1 \\
\hline Restricted joint mobility (hip,knee or ankle) & 10 & 8 & 4 & 1 \\
\hline
\end{tabular}

Table-8 Composite Functional Outcome (Calstorm \& olerud criteria)

\begin{tabular}{|c|c|c|c|c|}
\hline Outcome & Excellent & Good & Acceptable & Poor \\
\hline No. of cases & 4 & 10 & 8 & 1 \\
\hline
\end{tabular}


Table-9 Outcome of intra-articular fractures

\begin{tabular}{|l|c|c|c|c|}
\hline Criteria & Excellent & Good & Acceptable & Poor \\
\hline Non articular & 4 & 10 & 2 & 0 \\
\hline Intra-articular-Tibia alone & 0 & 0 & 2 & 0 \\
\hline Intra-articular-Femur alone & 0 & 0 & 4 & 0 \\
\hline $\begin{array}{l}\text { Intra-articular } \\
\text { Both femur and tibia }\end{array}$ & 0 & 0 & 0 & 1 \\
\hline
\end{tabular}

Table-10 Outcome based on Implants / Treatment methods

\begin{tabular}{|l|c|c|c|c|}
\hline Criteria & Excellent & Good & Acceptable & Poor \\
\hline Femur nail + tibia nail & 4 & 4 & 0 & 0 \\
\hline Tibia nail +femur plate & 0 & 1 & 1 & 0 \\
\hline Tibia plate + femur nail & 0 & 3 & 3 & 0 \\
\hline Ex-fix for tibia + nail for femur & 0 & 2 & 0 & 0 \\
\hline Ex-fix for tibia + plate for femur & 0 & 0 & 3 & 0 \\
\hline Tibia plate + femur plate & 0 & 0 & 1 & 1 \\
\hline
\end{tabular}

\section{Discussion}

In our study mean age of the patient who sustained floating knee injuries was 31 years and median age 27 years. Only one female was there among the 23 patients of floating knee injuries .Motor vehicular accident accounts for $26 \%$ and motor cycle accident accounts for $65 \%$. Right side was involved in $78 \%$ of cases .Most cases were Blake and Mcbryde classification Type-1 accounting for about $65 \%$.In 30\%patients had involvement of knee joint either as intra articular tibial or femur fracture. Compound fractures were treated initially by external fixation followed by definitive internal fixation. 55\% had fixation with interlocking nail. Healing time for comminuted intra articular fracture in case of femur was 4 months and that of tibia was 4.5 months. When ILN was used for femur fixation the union occurred in about three months .In the case of tibia, about an average of 4.5 months was required to attain union. Functional outcome dependon the type of fractures and the implants used for fixation. $p$ value calculated using chi square test was 0.0023 suggestive of significant association between comminution of fracture and functional outcome. $P$ value using chi square test had a value of 0.001 showing significant association between intra -articular distribution and functional outcome. When the type of implant used was compared to functional outcome, nailing of both tibia and femur yielded the best outcome while plating of both yielded the worst outcome.$P$ value calculated was there 0.028 and was found to be significant.

\section{Summary}

Assessment of functional outcome was done using Kalstorm and Olerud criteria after attaining bony union. Fracture union in most cases were obtained in an average of 3 months to 4.5 months .Among the study group $43 \%$ did not have any subjective symptoms from thigh knee or leg. Walking ability was unimpaired in $48 \%$ of patients, $26 \%$ had slight difficulty in walking and walking distance was restricted in $22 \%$ of patients. $1 \%$ had severe limitation of walking. No significant shortening was observed. Majority had useful range of knee movements.18\% had moderate (20-40 degree) limitation and in one patient there was severe limitation of knee movement. The outcome was poor in case of intra articular distribution and comminuted fractures and excellent in case were primary internal fixation was done using intramedullary nailing of both tibia and femur fractures.

\section{Conclusion}

From my study I conclude that

1. Floating knee injuries are due to high velocity trauma

2. Motor cycle accidents were the most common cause 
3. Males are affected more

4. Right sided involvement is more common.

5. Internal fixation of fractures permit early mobilization of knee joint with good functional outcome.

6. Intra-articular distribution of fractures yielded poor functional outcome.

7. Intramedullary nailing of fractures allowed early mobilization of knee joint with excellent functional outcome.

\section{References}

1. Letts M, Vincent N, Gouw G. The" floating knee "in children .J Bone Joint Surg Br 1986 May;68(3):442-46

2. Blake R, McBryde A Jr. The floating knee: ipsilateral fractures of femur and tibia. South Med J 1975 Jan 68(1);13-6

3. Karlstorm G, Olerud S. Ipsilateral fractures of the femur and tibia. $\mathrm{J}$ bone Joint Surg Am 1977 Mar :59(2):240-43

4. Bansal VP, Singhal V, Mam MK, Giil SS The floating knee. 40 cases of ipsilateral fractures of the femur and the tibia. In Orthop 1984:8(3);184-87

5. Floating knee fractures (ipsilateral fracture of femur and tibia) -treatment by closed Ender nailing. Nippon Seikeigeka Gakkai Zass hi 1984 May ;58(5) ; 475-83

6. O strum. Treatment of floating knee injuries through a single percutaneous approach. Clin Orthop Relat Res 2000 June 375:43-50

7. Behr JT, Apel DM, Pinzur MS, Dobozi WR, Behr MJ. Flexible intramedullary nail for ipsilateral femoral and tibial fractures. J Trauma 1987 Dec ; 27(12) : 135457

8. Lundy DW, Johns on KD "floating Knee" injuries: ipsilateral fractures of femur and tibia. J Am Acad orthop Surg 2001 Jul Aug: 9(4): 238-45.
9. Rethnam U, Yesupalan RS, and Nair R. The floating knee: epidemiology, prognostic indication and outcome following surgical management. J Trauma manage outcome 2007:1-8.

10. Ulfin Rethnam Rajam Syes Upalan and Rajagopalan Nair, The floating knee; outcome following Surgical ManagementJ Trauma Management and outcomes.

11. Gregory P, Di Cicco J, Karpic K Di Pas qale T, Hers covici, Sanders R. Ipsilateral fractures of the femur and tibia: treatment with retrograde femoral nailing and undreamed tibial nailing. J Orthop Trauma 1996: 10 (5):309-16

12. Veith Rg. Winquist RA, Hansen ST Jr. Ipsilateral fractures of femur and tibia. A report of fifty seven consecutive cases. J Bone Joint surg Am 1984 sept 66(7):9911002

13. Katada S , Ando K, NaKagawa K, Yamada T, Sasamoto H , Kawabe N et al.

14. Theodoratos G, Papanikolaou A, Apergis E, Maris J: simultaneous ipsilateral diaphyseal fractures of the femur and tibia: treatment and complications. Injury 2001: 32(4);313-15

15. Singaravadin vaidyanathan, Jagannath Panchanatham, Ganes an, and Mugundhan Floating Knee injury associated with a case report and review of literature 2012 , articles Id 913230. 